\title{
Determination of Self-efficacy and Burnout State of Teachers Working in the Special Education Field in Terms of Different Variables
}

\author{
Cahit Nuri ${ }^{1}$, Mukaddes Sakalli Demirok ${ }^{1}$, Cemaliye Direktör ${ }^{2}$ \\ ${ }^{1}$ Near East University, Faculty of Education, Department of Special Education, Nicosia, Turkish Republic of Northern \\ Cyprus Mersin 10, Turkey \\ ${ }^{2}$ European University of Lefke, Department of Psychology, Lefke, Turkish Republic of Northern Cyprus Mersin 10, \\ Turkey
}

Correspondence: Cahit Nuri, Department of Special Education, Near East University, Nicosia, Turkish Republic of Northern Cyprus Mersin 10 Turkey, Postal Code: 922022, Turkey.

\author{
Received: January 24, $2016 \quad$ Accepted: February 4, $2017 \quad$ Online Published: February 20, 2017 \\ doi:10.11114/jets.v5i3.2237 URL: https://doi.org/10.11114/jets.v5i3.2237
}

\begin{abstract}
The aim of the study is to analyse the self-efficacy and burnout of special education teachers in terms of different variables such as gender, teachers' educational levels, teachers' daily working hours, and teachers' daily student numbers.

7 special education schools, affiliated to Turkish Republic of Northern Cyprus (TRNC) Ministry of Education Primary Education Management Office, and 21 schools, which have a special education mainstreaming room, constituted the population of the research. 46 special education teachers working at special education institutions and 24 special education teachers working at a mainstreaming room in primary schools (a total number of 70 teachers) constituted the sample of the research.

The Maslach Burn-out Scale and Teacher Self-Efficacy Scale were administered to the sample group. The collected data was entered into the SPSS and analysed using a t-test, Mann Whitney U and Kruskal Wallis.

The working hours of teachers were found to be statistically significant for sufficiency in engagement of student sub-dimension. It was revealed that teachers with fewer working hours had lower self-efficacy scores than the teachers with more working hours. Statistically significant difference was also found in depersonalization of burnout sub-dimension of teachers according to their professional seniority.
\end{abstract}

Keywords: burn-out, self-efficacy, special education, teachers

\section{Introduction}

The field of special education is thought to be an education field whose importance has increased rapidly in recent years. When educational rights are evaluated equally, the value given to the education quality taken by individuals showing different developmental characteristics also increases. The special education field is evaluated as a rather difficult field when the qualitative and quantitative sides of the work done are considered (Tatar, 2004).

Special education is defined as an education programme that is presented and developed by specialists in order to provide educational and social requirements to individuals showing significant levels of personal and developmental difference from their peers (Ataman, 2003) (Special Education Service Legislation, 2012). Since special education teachers are more frequently in interaction with their students than other teachers, they experience a burnout state more often (Girgin and Baysal, 2005). Burnout is defined as negative emotions (Goddard and Goddard, 2006) that affect the individual emotionally, cognitively, physiologically and cause them to experience stress (Yan and Jian-xin, 2007).

Research related with burnout showed that burnout occurs in professions wherein individuals must frequently interact with people face-to-face and it decreases the efficiency at work, negatively affects the psychological health of the individuals, and leads to emotional burnout as well (Izgar, 2001). Emotional burnout is defined as a shortage of emotional and physical sources of individuals, whereas the depersonalization sub-dimension is defined as negative attitudes and unresponsiveness in interpersonal relations. On the other hand, the other sub-dimension, personal success, is indicated as negative judgement that an individual owns towards himself regarding his work (Maslach, Schaufeli and 
Leiter, 2001). Burnout affects individuals, developing negative attitudes towards their abilities (Tang, Au, Schwarzer and Schmitz, 2001). Burnout carries a risk factor for profession groups in which interpersonal communication and interaction is more intense (Croom, 2003). Burnout gives harm to both teacher and student by decreasing the quality of education (Yan and Jian-xin, 2007). Psychological (depression and anxiety), physiological (continuous headache, fast heartbeat, high pressure), and/or behavioral (smoking, drinking and continuous sleeping problems) problems show that the teaching profession is related to stress (Tugrul and Celik, 2002).

It is reported that the burnout level of special education teachers shows significant difference in terms of gender, education level, and working hours. However, there is not a significant difference in terms of self-efficacy (Karahan and Uyanık Balat, 2011). Generally, there was difference between males and females in the scope of burnout levels and types, but it is presented that burnout level decreases as education level increases, burnout level increases during young adulthood, burnout is observed more in singles compared to married teachers, there is a low level of burnout in teachers working in the country and low prestige institutions than the ones working in city and high prestige institutions (Karakelle and Canpolat, 2008). According to Çokluk (2001), teachers take roles in education of a few generations and it is an occupational group in which burnout is observed. It is reported that teachers have many stressors, such as problems between teachers and parents, behavioral problems, and new educational methods (Skaalvik and Skaalvik, 2010). Teachers that face various stress-creating situations experience burnout more. The previous studies show that there are findings regarding that teachers working with needy individuals experience burnout earlier and more often than the teachers working with individuals with normal development (Cokluk, 1999; Başaran, 1999; Ozmen, 2001).

Self-efficacy obtains how much effort an individual makes in case of difficult situations (Hazır Bıkmaz, 2002). Self-efficacy is conceptualised as a level of believing in the ability of individuals regarding making plans, organisation, and application towards qualifications about education (Skaalvik and Skaalvik, 2010). Friedman and Kass (2000) explain self-efficacy perception for teachers with a conceptual model of two fields as school and classroom. It is expressed that teachers with low self-efficacy perception have more negative student relations, less tolerance and criticise students more than the teachers with high self-efficacy perception (Pajares, 1992). Teachers showing positive attitudes towards education and students cause them to feel themselves to be more sufficient so their self-efficacy perception increases. In accordance, identifying factors that affect burnout and self-efficacy play an important and effective role in coping with burnout (Surgevil, 2006). Telef (2011) suggests steps that strengthen self-efficacy and lessen the sense of burnout should be taken in education system. Self-efficacy is explained as the perception of an individual regarding what he is going to do (Bandura, 1986). The perception of self-efficacy is suggested to be a factor in coping with burnout (Surgevil, 2006). Satıc1 (2013) emphasizes the importance of self-efficacy perception and sense of burnout of special education teachers that work with needy children since they show much patience and devotion, give long term, and comprehensive education under more difficult conditions.

An examination of the burnout state, self-efficacy perception and emotional state of teachers working in different education conditions with different disabled groups, is thought to be important. This study aimed to examine burnout, self-efficacy perceptions and emotional states of teachers in terms of demographical factors and obtain relation levels with these factors. Based on this aim, the sub-aims given below attempted:

1. Is there a significant difference between self-efficacy perceptions of special education teachers in terms of gender, age, educational level, professional seniority, daily student number, and daily working hour?

2. Is there a significant difference between burnout levels of special education teachers in terms of gender, age, educational level, professional seniority, daily student number, and daily working hour?

3. Is there a relationship between burnout levels, self-efficacy perceptions, and emotional states of special education teachers?

\section{Materials and Method}

\subsection{Research Model}

In this research, since it was aimed to obtain the description of the present situation, the existence or degree of change between two, or more, variables in order to identify burnout levels, self-efficacy perceptions, and emotional states of teachers working in special education institutions, a relational scanning model was used.

\subsection{Population and Sampling}

The population of the research is formed of 21 schools, 7 of which are Special Education schools and Special Education activity rooms that belong to the Directorate of Primary Education of Ministry of Education of Turkish Republic of Northern Cyprus during 2012-2013 Academic year Spring term. 46 special education teachers that are working in Special Education Institutions and 24 special education teachers that are serving in activity rooms of primary schools (70 people total) formed the sampling of research. In the study done, 66 special education teachers were reached. 


\subsection{Collection of Data}

\subsubsection{Personal Information Form}

For related demographic properties of teachers, data regarding age, gender, educational level (undergraduate, post graduate), professional seniority, daily working hours, and daily student numbers were collected.

\subsubsection{Teacher Self-efficacy Scale}

In order to obtain the self-efficacy perceptions of teachers, the "Teachers Sense of Efficacy Scale" (TSES) form, that was developed by Tschannen-Moran and Woolfolk Hoy (1998), was used. This scale was developed based on the teacher efficacy scale of Bandura. A Turkish adaptation of "Teachers Sense of Efficacy Scale" (TSES) was done by Capa, Cakıroğlu and Sarıkaya (2005). Capa and his colleagues (2005) named the scale "Turkish Version of the Teachers Sense of Efficacy Scale" (TTSES). At the end of the research done on 628 Turkish teacher candidates, the researchers found the reliability values as for self-efficacy to be 0.93 , efficacy for student engagement 0.82 , efficacy in instructional strategies 0.86, and efficacy in classroom management 0.84. The final version of the scale consisted of three sub-dimensions. In the long form, each dimension involves 8 questions and in total there are 24 questions. The sub-dimensions are efficacy in student engagement, efficacy in instructional strategies, and efficacy in classroom management.

\subsubsection{Maslach Burnout Scale}

The questionnaire that was developed by Maslach and Jackson (1981) is a septavalent likert type scale. The scale consists of 22 items and evaluates three sub-dimensions of burnout. Among these items, three were removed by Ministry of National Education since they were considered as unsuitable, so there are 19 items total. The Maslach burnout scale involves three sub-dimensions of burnout. The first sub-dimension is emotional burnout sub-dimension that consists of 8 items. The second scale is the depersonalization sub-dimension, which consists of 3 items. The third scale is the personal success sub-dimension, which consists of 8 items. Scale items are scored as "1 never" to "7 always". In scales that were translated into Turkish, some changes were made and the choices were regulated in pentavalent form, as " 0 never" and " 4 always", which is different from its original septavalent form. The high degree of burnout reflects the high point in emotional exhaustion and depersonalization sub-dimensions and low point in personal achievement sub-dimension. As a medium level of burnout reflects the medium level of scores in each of the three sub dimensions, low scores in emotional exhaustion and depersonalization sub-dimensions and high scores in personal success sub-dimension reflect low levels of burnout. The validity and reliability study of scale was done by Çapri (2006). The reliability coefficients of sub dimensions of the scale were found to be depersonalisation $=0.72$, personal achievement $=0.67$.

In this research, burnout was separated into three groups as low, medium, and high by taking the maximum point that can be obtained from the scale into consideration. Minimum scores were taken out from maximum scores that can be obtained from sub-dimensions and break scores for this research were found by dividing obtained point into three. Accordingly:

In the emotional exhaustion sub-dimension, the scores 30 and over are accepted as burnout and if scores change between 19-29 it is accepted as medium, 8-18 is accepted as low level. In the depersonalisation sub-dimension the scores 23 and over are accepted as burnout and if scores change between 15-22 it is accepted as medium, 6-14 is accepted as low level.

In the personal achievement sub-dimension, the scores 30 and over are accepted as burnout, and if scores change between 19-29 it is accepted as medium, 8-18 is accepted as low level.

\subsection{The Analysis and Intrepretation of Datas}

In analysing the scales, SPSS Statistical Programme (SPSS 17.0) was used. Whereas, in analysing the data, arithmetical mean, difference analysis test between two means ( $t$ ), Mann Whitney U test and Kruskal Wallis tests were used.

\section{Results}

\section{T-Test Findings Regarding Self-Efficacy Perception of Special Education Teachers According to Genders}

As seen in Table 1, according to the results of the t-test analysis done for independent groups, there is not a significant difference between general self-efficacy $(t(66)=.75 ; p>.05)$ and the genders of teachers. There was a significant difference in favour of female teachers in scores of efficacy in student engagement $(t(66)=2.97 ; p>.05)$, efficacy in instructional strategies $(\mathrm{t}(66)=2.20 ; \mathrm{p}<.05)$, and efficacy in classroom management $(\mathrm{t}(66)=2.38 ; \mathrm{p}<.05)$ sub-dimensions $(\mathrm{p}<.05)$.

According to the et square $(\eta)$ values that were calculated to test the effect size of gender independent variable on 
self-efficacy perceptions of teachers, it can be said that the gender of teachers have effect on self-efficacy and its sub-dimensions $(\eta=.113)$ (Table 1$)$.

According to the results of the t-test analysis, there is not a significant difference between burnout levels $(\mathrm{t}(66)=.52$; $\mathrm{p}>.05)$, depersonalization $(\mathrm{t}(66)=.45 ; \mathrm{p}>.05)$, personal achievement $(\mathrm{t}(66)=1.16 ; \mathrm{p}>.05)$, emotional exhaustion $(\mathrm{t}(66)=.15 ; \mathrm{p}>.05)$ and genders of teachers (Table 1$)$.

Table 1. T-Test Findings Regarding Self Efficacy Perception of Special Education Teachers According to Genders

\begin{tabular}{|c|c|c|c|c|c|c|c|c|c|}
\hline Dimension & Gender & $\mathrm{N}$ & $X$ & $\mathrm{~S}$ & $\mathrm{Sd}$ & $\mathrm{T}$ & $\mathrm{P}$ & Explanation & $\eta$ \\
\hline \multirow{2}{*}{ Efficacy in Student Engagement } & Female & 35 & 7.64 & 0.71 & \multirow{2}{*}{66} & \multirow{2}{*}{2.979} & \multirow{2}{*}{$.00^{* * *}$} & Difference & \multirow{2}{*}{0.402} \\
\hline & Male & 33 & 7.11 & 0.76 & & & & $\mathrm{P}<0.05$ & \\
\hline \multirow{2}{*}{ Efficacy in instructional Strategies } & Female & 35 & 7.89 & 0.59 & \multirow{2}{*}{66} & \multirow{2}{*}{2.2} & \multirow{2}{*}{$.03^{*}$} & Difference & \multirow{2}{*}{0.301} \\
\hline & Male & 33 & 7.51 & 0.83 & & & & $\mathrm{P}<0.05$ & \\
\hline \multirow{2}{*}{ Efficacy in Classroom Management } & Female & 35 & 7.90 & 0.63 & \multirow{2}{*}{66} & \multirow{2}{*}{2.381} & \multirow{2}{*}{$.02^{*}$} & Difference & \\
\hline & Male & 33 & 7.50 & 0.75 & & & & $\mathrm{P}<0.05$ & 0.078 \\
\hline \multirow{2}{*}{ General Self-efficacy } & Female & 35 & 7.35 & 0.92 & \multirow{2}{*}{66} & \multirow{2}{*}{0.756} & \multirow{2}{*}{.45} & Insignificant Difference & \multirow[b]{2}{*}{0.113} \\
\hline & Male & 33 & 7.19 & 0.81 & & & & $\mathrm{P}>0.05$ & \\
\hline
\end{tabular}

$* \mathrm{p}<.05, * * \mathrm{p}<.01, * * * \mathrm{p}<.001$

\section{The Comparison of Self-efficacy of Teachers According to Educational Level of Teachers'}

According to education level, self-efficacy perceptions of special education teachers were obtained by Mann-Withney U analysis. There was found to be a significant difference between self-efficacy of undergraduate teachers (mean rank=31.05) and postgraduate teachers (mean rank=44.08) in efficacy in the student engagement sub-dimension $(u=277,50, p<0.05)$. Efficacy in instructional strategies and efficacy in classroom management did not differ between undergraduate and postgraduate educations (Table 2). Karahan (2008), in his study, similarly obtained that there is a not significant difference between self-efficacy of teachers according to their educational levels.

According to the results, there is not a significant difference between burnout levels and teachers' educational levels.

Table 2. The Comparison of Self-efficacy of Teachers According to Educational Levels of Teachers' (Mann-Withney U Test Results)

\begin{tabular}{lllllll}
\hline Dimension & Educational Level & $\mathrm{N}$ & Mean Rank & Rank Total & $\mathrm{U}$ & $\mathrm{P}$ \\
\cline { 2 - 6 } \multirow{2}{*}{ Efficacy in Student Engagement } & Undergraduate & 50 & 31.05 & 1552,5 & \multirow{2}{*}{$01^{*}$} \\
\cline { 2 - 5 } & Post Graduate & 18 & 44.08 & 793,50 & & \\
\hline
\end{tabular}

$* \mathrm{p}<.05$

\section{The Comparison of Self-efficacy Scores s of Teachers According to Their Daily Working Hours}

As it is seen in Table 3, the difference in self-efficacy perception of teachers working 1-4 hours daily (mean rank=30,81) and teachers working 5 hours or more daily (mean rank=43,35) was found to be significant $(u=303,000, p<0.05)$. It was also observed that in efficacy in student engagement, self-efficacy of teachers working 1-4 hours daily are lower than the ones working 5 hours or more daily. There is not a significant difference between efficacy in instructional strategies, efficacy in classroom management, and teachers' daily working hours.

Table 3. The Comparison of Self-efficacy Scores s of Teachers According to Their Daily Working Hours (Mann-Withney U Test Results)

\begin{tabular}{|c|c|c|c|c|c|c|}
\hline Dimension & Daily Working Hour & $\mathrm{N}$ & Mean Rank & Rank Total & $\mathrm{U}$ & $\mathrm{P}$ \\
\hline \multirow[b]{2}{*}{ Efficacy in Student Engagement } & 1-4 working hours & 48 & 30,81 & 1479,0 & & \\
\hline & 5 and over working hours & 20 & 43,35 & 867,00 & 303,00 & $.01^{*}$ \\
\hline
\end{tabular}

\section{The Comparison of Self-efficacy Scores of Teachers According to Their Daily Student Numbers}

In order to obtain whether daily student numbers and self-efficacy perception of teachers differ significantly or not, the Mann-Whitney U analysis was applied. Since the number of students that teachers work with do not show normal distribution, the nonparametric test was used.

In Table 4, there was found to be a statistically significant difference between self-efficacy perceptions of teachers working with 1 and 3 students (Mean range=23.59) and teachers working with 4 or more students (Mean range $=36.61$ ) in the efficacy in classroom management sub-dimension $(u=193,500, p<0.05)$. Based on this finding, it can be said that the self-efficacy perception of teachers increases in accordance with increasing number of students $(\mathrm{p}>0.05)$.

Teachers' perceptions of efficacy in student engagement and efficacy in instructional strategies did not differ based on their daily working hours. In addition, there were no significant difference between burnout levels and teachers' daily working hours. 
Table 4. The Comparison of Self-efficacy Scores of Teachers According to Their Daily Student Numbers (Mann-Withney U Test Results)

\begin{tabular}{|c|c|c|c|c|c|c|c|c|}
\hline Dimension & & $\begin{array}{l}\text { According to Number of } \\
\text { Students }\end{array}$ & $\mathrm{N}$ & $\begin{array}{l}\text { Mean } \\
\text { rank }\end{array}$ & $\begin{array}{l}\text { Rank } \\
\text { Total }\end{array}$ & $\mathrm{U}$ & $\mathrm{P}$ & Explanation \\
\hline \multirow{2}{*}{$\begin{array}{l}\text { Efficacy in } \\
\text { Management }\end{array}$} & \multirow[t]{2}{*}{ Classroom } & 1-3 number of students & 11 & 23,59 & 259,50 & \multirow[b]{2}{*}{193,50} & \multirow[b]{2}{*}{.04} & $\mathrm{P}<0.05$ \\
\hline & & $\begin{array}{l}4 \text { and over number of } \\
\text { students }\end{array}$ & 57 & 36,61 & 2086,50 & & & $\begin{array}{l}\text { Significant } \\
\text { Difference }\end{array}$ \\
\hline
\end{tabular}

$* \mathrm{p}<.05$

\section{The Comparative Results of General Average Scores of Burnout Levels of Teachers According to Their} Professional Seniority

In order to obtain whether there is significant difference between the experiences of teachers towards the teaching profession and their burnout levels, the Kruskal Wallis $\mathrm{H}$ test was applied. It was found that there is a statistically significant difference in the burnout depersonalisation sub-dimension according to their professional seniority $(\mathrm{X} 2=8.171, \mathrm{p}<.05)$. It was observed that burnout levels of teachers with $1-5$ years of professional seniority is "medium", whereas the ones with 11-15 years and 16 or more years of professional seniority have "high" levels of burnout (Table 5).

Burnout levels, emotional exhaustion, and personal achievement were not found to be significant in teachers' professional seniority. In addition, there is not a significant difference between self-efficacy and professional seniority.

Table 5. The Comparative Results of General Average Scores of Burnout Levels of Teachers According to Their Professional Seniority (Kruskal Wallis H Test Results)

\begin{tabular}{|c|c|c|c|c|c|c|c|}
\hline Dimension & $\begin{array}{l}\text { Professional } \\
\text { Seniority }\end{array}$ & $\mathrm{N}$ & Mean Range & $\mathrm{Sd}$ & $\mathrm{X}^{2}$ & $\mathrm{P}$ & Explanation \\
\hline \multirow{4}{*}{ Depersonalisation } & $1-5$ years & 6 & 17.83 & \multirow{4}{*}{3} & \multirow{4}{*}{8.171} & \multirow{4}{*}{$.04^{*}$} & \\
\hline & $6-10$ years & 27 & 30.87 & & & & $\mathrm{P}<0.05$ \\
\hline & $11-15$ years & 16 & 40.00 & & & & Significant \\
\hline & 16 years and over & 19 & 40.29 & & & & Difference \\
\hline
\end{tabular}

* $\overline{\mathrm{p}<.05}$

\section{Discussion and Conclusion}

In the research that was done to obtain burnout, self-efficacy, and the emotional state of teachers working in special education institutions, a description of the present situation and existence or degree of covariance between two, or more than two, variables, it was obtained that teachers perceive themselves as very sufficient in general self-efficacy and efficacy in student engagement sub-dimensions, whereas in the sufficient in education strategies and in classroom management dimensions, they perceive themselves as rather sufficient.

When the self-efficacy scores of special education teachers are examined according to gender, both male and female teachers perceive themselves as rather sufficient in their general self-efficacies. In the efficacy in student engagement sub-dimension, female teachers perceive themselves as very sufficient whereas male teachers perceive themselves as rather sufficient.

It was obtained that special education teachers perceive themselves as very sufficient in efficacy in education strategies and efficacy in classroom management. There was no significant difference observed between self-efficacy perceptions and gender of teachers. In efficacy in student engagement, efficacy in education strategies and efficacy in classroom management sub-dimension scores according to gender there was a significant difference in favour of female teachers.

According to the et square $(\eta)$ values that were calculated to test the effect size of the gender independent variable on self-efficacy perceptions of teachers, it can be said that the gender of teachers has an effect on self-efficacy and its sub-dimensions $(\eta=.113)$. Woolfolk-Woolfolk Hoy and Minner (2002), in their studies, show that self-efficacy perception level is affected by gender. In most of the studies of Yaman, Cansungu and Altuncekic (2004), and Akbas and Celikaleli (2006) they obtained that gender does not affect self-efficacy perception level.

According to educational levels there obtained a significant difference between self-efficacies of undergraduate teachers and post graduate teachers in efficacy in student engagement dimension. Similarly Karahan (2008) in his study obtained that there is a not significant difference between self-efficacy of teachers according to their educational level.

According to daily working hours of special education teachers, there was found a significant difference between teachers working 1-4 hours and 5 or more hours. Karahan (2008), in his study, obtained that the self-efficacy perception of teachers does not show a significant difference according to daily working hours.

In order to obtain whether daily student numbers and the self-efficacy perception of teachers differ significantly or not, 
the Mann-Whitney U analysis was applied. Since the number of students that teachers work with does not show normal distribution, nonparametric test was used.

In this situation, there was found to be a statistically significant difference between the self-efficacy perceptions of teachers working with 1 to 3 students and teachers working with 4 and more students in the efficacy in classroom management sub-dimension. Based on this finding, it can be said that the self-efficacy perception of teachers increases in accordance with an increasing number of students. Similarly, Karahan (2008), as a result of his study, found that there is a significant difference in the self-efficacy of teachers according to daily student number.

When the arithmetic mean of the scores of special education teachers from burnout scale are examined, it was found that emotional burnout levels, depersonalisation levels and personal success levels are at high levels. According to the results obtained from general burnout levels, the average scores of special education teachers are higher than others in total the burnout scores dimension. From the obtained arithmetic average scores, the high point obtained from the emotional burnout and depersonalisation sub-dimensions show the high level of burnout, the low point obtained from the personal success sub-dimension shows, again, that they experience high level of burnout.

It was found that there is a statistically significant difference in the burnout depersonalisation sub-dimension of special education teachers according to their professional seniority. It was observed that burnout levels of teachers with 1-5 years of professional seniority is "medium", whereas, the ones with 11-15 years and 16 years of professional seniority and over have "high" levels of burnout. Oruc (2007) obtained that according to the working period variable for burnout, depersonalisation, and personal success sub-dimensions belong to teachers with 1-5 years of experience. Sahin and Sahin (2012) found out personal success significantly differs according to Professional seniority.

In special education professionals who works with burnout and self-efficacy, can easy their work by finding out information about teacher's characteristic properties. Further research can be work with different variables such as school climate, teacher's resilience, management of student behaviour problems.

Professional seniority was related to depersonalization of the teachers'. Since special education teachers are more frequently in interaction with their students than other teachers, they experience a burnout state more often (Girgin and Baysal, 2005). Special education teachers will benefit from psychological supports that become coping skills with this aspect of their work. Self-efficacy in student engagement was related to teachers' educational level and daily working hours. Teachers with more training in special education teaching and more experience also may feel more self-efficacy in student engagement because they experience more success at student engagement as a result of increased skills and knowledge.

\section{References}

Akbas, A. C. O. (2006). Examination of science teaching self-efficacy beliefs of classroom teacher candidates in terms of gender, study type and universities. Mersin University Education Faculty Magazine, 2(1).

Ataman, A. (2004). Needy children and special education. Ataman, A (Ed), Needy children and introduction to special education. Ankara: Umit Publication, 1st publication, 11-29.

Bandura, A. (1986). Social foundations of thought and action: A Social Cognitive Theory. Englewood Cliffs, NJ: Prentice-Hall.

Capa, Y., Cakiroglu, J., \& Sarıkaya, H. (2005). The development and validation of a Turkish version of teachers' sense of efficacy scale. Education and Science, 30(137), 74-81.

Cokluk, O. (1999). Estimation of burnout in teachers and managers serving in schools of children having mental and audial disability. (Unpublished post graduate thesis). Ankara University, Social Sciences Institution, Ankara.

Croom, D. B. (2003). Teacher burnout in agricultural education. Journal of Agricultural Education, 44(2).

Friedman, I. A., \& Kass, E. (2002). Teacher self-efficacy: A classroom-organization conceptualization. Teaching and teacher education, 18(6), 675-686.

Girgin, G., \& Baysal, A. (2005). An example for burnout: special education educator's burnout level and some variables. Turkish Armed Forces Preventine Medicine Journal, 4(4), 172-187.

Goddard, R., \& Goddard, M. (2006). Beginning teacher burnout in queensland schools: associations with serious intentions to leave. The Australian Educational Researcher, 33(2), 61-75.

Hazir, B. F. (2002). Self-efficacy belief scale in science education. Education Sciences and Application, 1(2), 197-210.

Izgar, H. (2001). Burnout levels of school managers. Magazine of Education Management in Theory and Application, $27,335-340$. 
Karahan, S. (2008). Examining of burnout levels and self-efficacy perceptions of educators working in special education schools. (Post graduate thesis). Marmara University, Education Sciences Institution, Special Education Departmant, Department of Mentally Handicapped Teaching, Istanbul.

Karahan, S., \& Uyanık, B. G. (2011). Examining of burnout levels and self-efficacy perceptions of educators working in special education schools. Pamukkale University Education Faculty Magazine, 29, 1-14.

Karakelle, S., \& Canpolat, S. (2008). Burnout level examining of approaches of higher education teachers towards students. Education and Science, 147(33), 106-120.

Maslach, C., \& Jackson, S. E. (1981). The measurement of experienced burnout. Journal of Occupational Behaviour, 2, 99-133.

Maslach, C., Schaufell, W. B., \& Leiter, M. P. (2001). Job burnout. Annual Review of Psychology, 52, 397-422.

Oruc, S. (2007). Examining of burnout levels of teachers working in special education field in terms of some variables. (Master thesis). Cukurova University, Institute of Social Sciences, Department of Elementary Education, Adana.

Ozmen, H. (2001). Gorme engelliler okullarında gorev yapan ogretmenlerin, tukenmislik duzeyleri. (Unpublished post graduate thesis). Gazi University, Social Sciences Institution, Ankara.

Pajares, F. (1992). Teachers' beliefs and educational research: cleaning up a messy construct. Review of Educational Research, 62, 307-332.

Sahin F, \& Sahin D (2012). Examining the burn-out level of special education teachers working with disabled individuals. Journal of Teacher Education and Educators, 1(2), 275-294.

Satici, A. S. (2013). Investigation of academic self-efficacy of university students in terms of various variables. (Post graduate thesis). Anadolu University, Education Sciences Institution, Eskişehir.

Skaalvik, E. M., \& Skaalvik, S. (2010). Teacher self-efficacy and teacher burnout: A study of relations. Teaching and teacher education, 26(4), 1059-1069.

Surgevil, O. (2006). Burnout Syndrome İn Business Life. (1st publication). Ankara: Nobel Publication.

Tang, C. S. K., Au, W. T., Schwarzer, R., \& Schmitz, G. (2001). Mental health outcomes of job stress among Chinese teachers: Role of stress resource factors and burnout. Journal of Organizational behavior, 22(8), 887-901.

Tatar, A. (2004). Etkili ögretmen. Yuzuncu Y1l Universitesi Egitim Fakultesi Dergisi, 1(2).

Telef, B. B. (2011). The study of teachers' self-efficacy, job satisfaction, life satisfaction and burnout. Elementary Education Online, 10(1), 91-108.

Tschannen, M. M., \& Woolfolk, H. A. (2001). Teacher efficacy: Capturing an Elusive Construct. Teaching and Teacher Education, 17(7), 783-805.

Tschannen, M. M., Woolfolk, H. A., \& Hoy, W. K. (1998). Teacher efficacy: Its meaning and measure. Review of Educational Research, 68(2), 202-248.

Tugrul, B., \& Celik, E. (2002). Working with normal children in Kindergarten Teacher Burnout. Pamukkale University Faculty of Education Journal, 12.

Woolfolk, H. A., Hoy, W. K. (1990). Prospective teachers' sense of efficacy and beliefs about control. Journal of Educational Psychology, 82(1), 81-91.

Yaman, S., Cansungu, O., \& Altuncekic, A. (2004). A research on the investigation of the self-sufficiency belief levels of the science education teacher candidates. Turk Egitim Bilimleri Dergisi, 2(3), 355-366.

Yan, Z., \& Jian, X. W. (2007). Burnout phenomenon of teachers under various conflict. US-Chaina Education Review, 4(1), 37-44.Allinder RM 1994. The relationship between efficacy and the instructional practices of special education teachers and consultants. Teacher Education and Special Education, 17, 86-95.

\section{Copyrights}

Copyright for this article is retained by the author(s), with first publication rights granted to the journal.

This is an open-access article distributed under the terms and conditions of the Creative Commons Attribution license which permits unrestricted use, distribution, and reproduction in any medium, provided the original work is properly cited. 